\title{
LA "PLENITUDO POTESTATIS" EN EL DEFENSOR MINOR DE MARSILIO DE PADUA
}

\author{
Pedro ROCHE ARNAS \\ Universidad de Alcalá
}

1.

La crítica a la plenitudo potestatis que se autoconfieren los Papas, es decir, la pretensión de ejercer un poder absoluto tanto en el ámbito religioso como en el temporal, manifestada de modo radical en la bula Unam Sanctam de Bonifacio VIII y raíz del conflicto que durante todo el medievo había enfrentado al papado $\mathrm{y}$ al imperio, constituye el nexo de unión del conjunto de la obra de Marsilio de Padua.

Como he señalado recientemente ${ }^{1}$, es fácil compartir la afirmación de J. Quillet ante la lectura del Defensor Minor. «Tenemos la impresión de que constituye una explicitación de tesis que no han sido siempre bien comprendidas y sobre las que Marsilio siente la necesidad de volver, no sólo para precisar su pensamiento y reafirmarlo ante los contradictores, sino también para desarrollar puntos que no habían sido más que esbozados en el Defensor Pacis, o bien porque le parecían lógicos o porque no habían adquirido todavía el carácter de actualidad que revestian en función de las circuns-

\footnotetext{
' Roche Arnas, Pedro: «La Ley en el Defensor Minor de Marsilio de Padua", Revista Española de Filosofía Medieval, número 2, 1995, pp. 91-99.

Endoxa: Series Filosóficas, $n^{\circ} 6,1995$, UNED, Madrid:

Pedro Roche: La "plenitudo potestatis" en el Defensor minor de Marsilio de Padua. pp. 241-262.
} 
tancias» ${ }^{2}$. Explicitación de tesis que no habían sido bien comprendidas o que estaban solamente esbozadas, el Defensor Minor es una prolongación de la segunda dictio del Defensor Pacis, del que retoma los temas esenciales de una manera selectiva ${ }^{3}$. La impresión, por otro lado, de responder a la polémica se confirma de acuerdo con el análisis comparado de los textos de Marsilio y de Ockham. Frente a la tesis de Brampton, que sitúa el Defensor Minor en 1342, pocos meses antes de la muerte de Marsilio, J. Quillet, siguiendo a Lagarde, lo sitúa en 1340-414: el Defensor Minor, tras la confrontación de los textos de Ockham y de Marsilio, sería una respuesta a la tercera parte del Dialogus de Ockham, el De Potestate Papae et Cleri, escrita entre los años 1339-40, que ataca con vehemencia las tesis eclesiológicas de Marsilio contenidas en el Defensor Pacis.

Explicitación de tesis ya defendidas, necesidad de responder a la polémica e intento de resolución de nuevos problemas, el Defensor Minor, de un modo mucho más concreto y posiblemente menos teórico o doctrinal, mantiene la coherencia y el objetivo básico del conjunto de la obra de Marsilio: devolver a la autoridad política las atribuciones que le son propias tanto en el ámbito temporal como espiritual, destruir en sus fundamentos la doctrina pontificia de la plenitudo potestatis.

\footnotetext{
${ }^{2}$ Quillet, J.: Marsile de Padoue, Oeuvres Mineures. Paris. Editions du Centre National de la Recherche Scientifique. 1979, p. 155-156

${ }^{3}$ «De quibus omnibus suppositis vel probatis, rememorata et etiam explicata sunt plura in hoc tractatu ex Maiori Pacis Defensore, per necessitatem tam sequentia quam deducta, propter quod Defensor Minor deinceps vocabitur tractatus iste. Amen. Laus Deo". Marsilio de Padua: Defensor Minor, edición francesa de J. Quillet, Marsile de Padoue, Oeuvres Mineures, Paris, Editions du Centre National de la Recherche Scientifique, 1979, XVI, 4. (En lo sucesivo citaremos todos los textos del D.M. por esta edición. El número romano corresponde al capítulo y el número arábigo al parágrafo).

4Es pues en el curso del año 1340 cuando el Defensor Minor fue retomado y terminado, quizá, al comienzo del año 1341, poco antes de que estallara el caso Maultasch. Esta fecha permite creer que Marsilio haya tratado en su obra los problemas del matrimonio, tras la solicitud por parte del Emperador de que diera su opinión sobre el asunto». Quillet, J.: op. cit., p. 159.
} 
La enseñanza del Maestro de las Sentencias, según la cual los sacerdotes tienen un cierto poder para atar y desatar, llamado comúnmente «poder de las llaves", excomulgando a los pecadores y alejándolos de la participación de los bienes tanto espirituales como civiles o temporales y de la asamblea de los otros fieles, constituye el horizonte de reflexión del Defensor Minor. En las primeras líneas del mismo se pregunta por la naturaleza de este poder y si, de algún modo, el poder o jurisdicción del emperador se debe a los obispos o a los sacerdotes ${ }^{6}$. Con objeto de responder a este interrogante, analiza qué debe entenderse por jurisdicción, ley y derecho, cuestiona y delimita los fundamentos mismos del poder espiritual de la Iglesia mediante una crítica detenida de algunas conclusiones derivadas del «poder de las llaves» por los defensores de la teocracia pontificia relativas a la confesión, al poder de los sacerdotes para infligir una penitencia real o personal en este mundo, a la concesión de indulgencias, a la liberación de las promesas o votos realizados y plantea, por último, si corresponde al Pontífice Romano tener cierta plenitud de poder por encima de los otros obispos o sacerdotes, por el hecho de ser el sucesor de San Pedro.

2.

Los fieles de Cristo, señala Marsilio de Padua, están regidos por una doble ley y viven bajo ella, la ley divina y la ley humana, de acuerdo con el doble fin al que está orientado en su existencia el ser humano, ultraterreno el uno y temporal el otro ${ }^{7}$. La ley divina «est praeceptum coactivum a Deo factum inmediate absque humana deliberatione, propter finem in futuro saeculo consequendum, et sub poena transgressoribus infligenda in eodem tantum-

\footnotetext{
${ }^{5}$ Mateo XVI, 1, 19. "Yo te daré las llaves del reino de los cielos, y cuanto atares en la tierra será atado en los cielos, y cuanto desatares en la tierra será desatado en los cielos".

${ }^{6}$ Marsilio de Padua. D.M. I, 1.

${ }^{7}$ Roche Arnas, Pedro: op. cit., pp. 94-95.
} 
modo saeculo, non praesenti ${ }^{8}$. La ley humana, sin embargo, es «praeceptum coactivum inmediate ab humana voluntate seu delibaratione procedens, propter finem inmediate in hoc saeculo consequendum, et sub poena in eodem solummodo transgressoribus infligendas?.

Hay claras analogías pero también evidentes diferencias entre ambos tipos de ley, de acuerdo con las definiciones dadas. Ambas, aunque cada una en su ámbito, posibilitan al hombre alcanzar el doble fin de la existencia humana al que hemos hecho alusión. $Y$ ambas prescriben con este objeto determinadas sanciones, es decir, tienen un carácter coactivo hasta el punto que sin esta cualidad no cabe hablar de norma juridica en sentido estricto. Es cierto que otros aristotélicos, y entre ellos Tomás de Aquino ${ }^{10}$, habían destacado la coactividad como un elemento necesario de la ley. Para Marsilio, sin embargo, no sólo es un elemento necesario sino que constituye una nota esencial de la misma.

Este carácter coactivo, como hemos indicado, conlleva un determinado tipo de sanciones. La sanción de la ley humana tiene lugar en este mundo, mientras que tendrá lugar en el mundo futuro la correspondiente a la ley divina. El legislador y juez coercitivo que juzga en función de la ley divina es Cristo. Por el contrario, según la ley humana «hay un legislador, el conjunto de los ciudadanos o su parte preponderante, o aún el príncipe supremo de los romanos, que se llama Emperador. Hay igualmente un juez coercitivo, como el conjunto de los ciudadanos ya dicho, o el príncipe, o aquél o aquéllos a quien o a quienes el conjunto de los ciudadanos o el príncipe ha dado autoridad y poder coercitivo para condenar con castigo real o personal en este mundo a los transgresores de la ley humana» ${ }^{11}$.

\footnotetext{
${ }^{8}$ Marsilio de Padua: D.M. XIII, 3 y I, 2.

${ }^{9}$ Marsilio de Padua: D.M. XIII, 3 y I, 4.

${ }^{10}$ Sto. Tomás de Aquino: Summa Theologica, I-II, q. 95, a.1: «Huiusmodi disciplina cogens metu poenae, est disciplina legum".

11 Marsilio de Padua: D.M., XIII, 9.
} 
La expresión «ab humana voluntate seu deliberatione procedens» de la citada definición de ley humana se llena de contenido con el texto anterior: es el conjunto de los ciudadanos o su parte preponderante ${ }^{12}$ la causa específica de la ley humana. Del mismo modo que al hablar de las formas de gobierno es la elección lo que define la rectitud de las mismas, y el consentimiento popular lo que legitima el poder, igualmente la legitimidad de la ley radica y se fundamenta en la voluntad popular. La ley es tal porque dimana de una voluntad soberana. Si para Tomás de Aquino la ley natural enmarca, fundamenta y llena de contenido y puntos de referencia a la ley positiva, Marsilio afirma la autonomía de la ley humana respecto de cualquier contenido que no responda a la voluntad popular. Es cierto que Marsilio considera que la ley «est santio sancta, iusta et honesta praecipiens, et prohibens inhonesta» ${ }^{13}$. Sin embargo, como señala García Cue, esta apelación al criterio de justicia para que podamos hablar de leyes perfectas «no radica tanto en su conformidad con la recta razón o con el Derecho Natural, tal como habían defendido prácticamente todos los aristotélicos precedentes, cuanto por depender de la voluntad del pueblo soberano, que es el único que puede determinar aquello que es más justo y útil para la ciudad, con lo que el aspecto formal de su doctrina legal, referido a la nota de coactividad, queda subrayado por su referencia a la voluntad del pueblo, conformadora, en el último término, de todo criterio de justicia»" ${ }^{14}$.

En casi todos los casos tanto la ley divina como la ley humana prescriben lo mismo. Pero no siempre, evidentemente. ¿A quién corresponde la sanción de hechos prescritos por ambas leyes? ¿A

\footnotetext{
${ }^{12}$ Juan Ramón García Cue realiza un buen análisis del término «valentior pars» y nos muestra las principales traducciones que del mismo han realizado los comentaristas de Marsilio, en «Teoría de la ley y de la soberanía popular en el Defensor Pacis de Marsilio de Padua", Revista de Estudios Políticos (Nueva Epoca), número 43, Enero-Febrero 1985, pág. 130.

${ }^{13}$ Marsilio de Padua. D.M., II, 5.

${ }^{14}$ García Cue, J.R.: op. cit., p. 144.
} 
quién corresponde la sanción en el caso de que un precepto de la ley divina no cristalice civilmente?

De nuevo afirma Marsilio la autonomía del poder civil y su exclusividad en el ejercicio de la coacción en este mundo. Es «al legislador humano y al juez humano, aunque no sea, por esencia, espiritual, a quien corresponde juzgar con juicio coercitivo y tener bajo el temor del castigo, sólo en este siglo, a los que cometen actos ilícitos» ${ }^{15}$, sean sacerdotes o laicos.

En el caso de no existir delito civil queda el juicio coercitivo reservado para Cristo en la otra vida. La función de los sacerdotes es enseñar y proclamar la naturaleza de lo que está prohibido o permitido, de modo semejante a como los médicos tienen que enseñar a actuar según los preceptos del arte médico para conservar o recuperar la salud del cuerpo. Pero, del mismo modo que los médicos no pueden obligar a un hombre a realizar un régimen útil infringiendo a los pacientes un castigo cualquiera, así los obispos o sacerdotes, médicos del alma, doctores o jueces según la ley divina, o los expertos en materia de derecho, es decir, los doctores de la ley humana, no pueden obligar a nadie en este mundo mediante castigo.

¿Podríamos concluir de lo afirmado que la ley divina o su legislador están subordinados a la ley humana? «Hay que señalar que si la ley divina prescribe hacer $u$ omitir algo que la ley humana no prescribe hacer u omitir, sino, a la inversa, que prescribe lo contrario o lo permite, se debe observar primero el precepto de la ley divina descuidando o abandonando la ley humana y su precepto o su autorización contraria. El precepto de la ley divina contiene, en efecto, la infalible verdad; el de la ley humana, no» ${ }^{16}$. Es evidente, por este texto y otros, que Marsilio no pretende, en modo alguno, subordinar los preceptos de la ley divina a la ley humana. De la lectura del mismo se desprende lo

\footnotetext{
${ }^{15}$ Marsilio de Padua: D.M., XV, 3.

${ }^{16}$ Marsilio de Padua: D.M., XIII, 6. No olvidemos, sin embargo, que la versión autorizada de la ley divina contenida en la Escritura corresponde al Concilio General.
} 
contrario. Siendo esto así, ¿puede seguir afirmando Marsilio la autonomía y soberanía de la sociedad civil y su capacidad para regular las relaciones y los actos humanos propios de la misma, y mantener, al mismo tiempo, la primacía de los preceptos divinos sobre los preceptos humanos? «Marsilio de Padua, aun admitiendo su espíritu laicizante y las progresistas innovaciones que introduce en su época, es, al mismo tiempo, un pensador anclado en la tradición medieval. A pesar de su heterodoxia, Marsilio sigue siendo un creyente que no encuentra necesario establecer un principio de incompatibilidad entre la vida cristiana y civil. Su crítica de las estructuras eclesiásticas está orientada a mostrar la desvirtuación que del cristianismo ha hecho la jerarquía clerical más bien que a atacar la vida cristiana misma. La exigencia para el creyente de acatar el precepto de la ley divina en este único caso concreto no contradice, a nuestro modo de ver, la independencia que establece entre ambos tipos de regulaciones ni la oportunidad de una cooperación mutua ${ }^{17}$. Lo que Marsilio pretende, en definitiva, no es la negación de los preceptos de la ley divina. Lo que intenta evitar es la instrumentalización de la legislación divina por un poder eclesiástico autónomo y su capacidad o autoridad para intervenir en el ordenamiento de la sociedad civil. Con este fin establece el Concilio General: existen preceptos de la ley divina, pero la interpretación autorizada de los mismos corresponde al Concilio General, dotado de la infabilidad que niega al Papa, y cuya convocatoria, como veremos, corresponde al Emperador, así como el garantizar coactivamente el cumplimiento de sus determinaciones.

3.

Habiendo negado a sacerdotes y obispos el poder jurisdiccional en sentido estricto, es decir, la capacidad de dictar la ley, Marsilio señala que es propio de los mismos transmitir o exponer la ley

${ }^{17}$ García Cue, J.R.: op. cit., p. 145. 
divina o el derecho. Y con el poder de trasmitir el derecho o la ley divina, Cristo confió a los apóstoles otros, tales como bautizar y celebrar el sacramento de la eucaristía, el poder de designar sucesores en las funciones sacerdotales y el poder de perdonar a los hombres los pecados en este mundo para alcanzar la beatitud en el otro.

Y dejando de lado el resto de los poderes citados, se centra en el último de ellos, el de absolver a los hombres de sus pecados, o el de no perdonárseles, llamado comúnmente, como hemos indicado, «poder de las llaves». ¿Cuál es su naturaleza? ¿En qué medida ha sido conferido a los obispos o sacerdotes?

\section{1.}

Los defensores de la teocracia pontificia inferían algunas conclusiones del citado "poder de las llaves». La primera de ellas era que cada hombre debe necesariamente, para su salvación eterna, confesar al sacerdote sus pecados cometidos contra la ley divina. Aducían quienes afirmaban esto que si tal confesión de los pecados no fuera necesaria, el "poder de las llaves" habría sido transmitido en vano a los apóstoles y a sus sucesores, lo que habría que rechazar por herejía.

Para Marsilio «basta confesar a solo Dios los pecados, es decir, reconocerlos y arrepentirse con el propósito de no cometer más ${ }^{18}$. La confesión al sacerdote es útil, en verdad, y puede ser provechosa en tanto que consejo de la Sagrada Escritura, no como precepto $^{19}$. Puede, sin embargo, ser objeto de prescripción por un

\footnotetext{
${ }^{18}$ Marsilio de Padua. D.M., V, 8: "Nos autem dicamus, secumdum Sacram Scripturam, nequaquam posse convinci, talem confessionem peccatorum fiendam sacerdotibus esse de necessitate salutis aeternae, sed utilem et fortasse expedientem, sicut sacrae Scripturae consilium, non praeceptum; sed sufficit soli Deo confiteri peccata ipsa, videlicet recognoscendo, et de ipsis penitendo cum proposito talia ulterius non committendi». Es evidente el tono prerreformador en el tema de la confesión, al igual que al hablar de las indulgencias, las peregrinaciones o el celibato eclesiástico.

${ }^{19}$ Diferencia entre consejo y precepto. «Sunt etiam quaedam permissa fieri et non fieri, quae sub praecepto affirmative vel negative non cadunt, et in lege
} 
Concilio General. En tal caso, aunque no esté prescrito ni prohibido por la Santa Escritura, debe ser observado por los fieles. De este modo, la obligación de confesarse ante un sacerdote radica no en un precepto de la ley divina sino en una decisión humana, la derivada de un Concilio General.

En cuanto al argumento aducido, señalando la inutilidad, en el caso de no ser necesaria la confesión al sacerdote, del poder atar y desatar trasmitido a los sacerdotes, señala Marsilio que aunque no hubiera habido jamás tal confesión, el "poder de las llaves» o de atar $y$ desatar es, en verdad, muy útil a los fieles para la salvación eterna: cuando los sacerdotes proclaman y denuncian abiertamente en la Iglesia que el no arrepentimiento de los pecados expone a la condenación eterna, los pecadores los reconocen y se afligen ante Dios, siendo desviados de la intención de cometerlos. De este modo, los sacerdotes pueden de manera muy útil atar y desatar a los pecadores sin la confesión. Se prueba, igualmente, con un argumento sacado de la Sagrada Escritura: dado que la confesión no es necesaria para que cualquiera sea atado en este mundo por la culpa y la pena de condenación eterna, del mismo modo la confesión no es necesaria para que alguien sea absuelto de la culpa y de la pena ${ }^{20}$.

El sacerdote no tiene poder real para atar y desatar. Sólo Dios lo posee. Pero si el poder que tienen los sacerdotes para atar y desatar, no es más que divulgar, hacer público o desvelar en presencia de la Iglesia a los que están atados o desatados ante Dios, ¿no bastará para perdonar a los delincuentes, aunque se carezca del carácter sacerdotal, ser versado en la Sagrada Escritura

divina quandoque vocata consilia; et sunt iam dicta permissa generaliora praeceptis,quoniam omne praeceptum fieri est permissum fieri, sed e converso non semper; similiter quoque omne prohibitum fieri permissum est non fieri, quamvis non e converso». (Marsilio de Padua, D.M., XIII, 3).

${ }^{20}$ Marsilio de Padua. D.M., V, 13. "Cum igitur non sit necessaria per hanc auctoritatem eius actio in ligando peccatorem, et coetera, ergo neque similiter in solvendo, sed sufficit sola contritio et vera poenientia de commisso absque omni confessione facta vel fienda sacerdoti, ut immediate absolvatur per Deum". 
y saber promulgar tales cosas en presencia de la Iglesia? ${ }^{21}$ Marsilio, que ha entregado al penitente a la sola mirada de Dios, reserva, sin embargo, únicamente a los sacerdotes el poder de la confesión en el sentido señalado. Solamente quienes tienen el habitus o carácter sacerdotal o gracia dada por profecía recibida de Cristo puede ejercer tal función, del mismo modo que quien no posee la licencia o poder de enseñar o juzgar al hombre sano o al enfermo pecaría contra la ley humana si ejerciera tal práctica sin autorización del legislador humano, aunque supiera.

3.2.

La segunda conclusión que algunos extraen del antedicho «poder de las llaves" afirma que todo sacerdote puede infligir a los pecadores una pena o penitencia personal o real en este mundo, debiendo aceptarla y cumplirla en la medida de sus fuerzas, sin lo cual no se le perdonan al pecador sus pecados.

No se puede probar por la Santa Escritura que tal poder o autoridad corresponda a los sacerdotes, señala Marsilio, ni determinar por cualquier otro argumento la cantidad y calidad de la pena que el pecador merece en el mundo futuro por los pecados que ha cometido en éste. El sacerdote puede aconsejar y señalar las consecuencias del pecado en la otra vida, pero no puede forzar una penitencia. El pecador, confesando sus pecados y arrepintiéndose sinceramente es librado de la pena de condenación eterna, incluso si no ha cumplido en este mundo ninguna penitencia real o personal ${ }^{22}$. Es probable, sin embargo, que el pecador sea castigado más o menos duramente y durante más o menos tiempo en el otro mundo, pero no eternamente, si no realiza ninguna reparación. Por ello, cumplir penitencia en este mundo es un consejo, no un precepto.

${ }^{21}$ Marsilio de Padua. D.M., V, 14.

${ }^{22}$ Marsilio de Padua. D.M., VI, 1. 


\section{3.}

La tercera conclusión inferida del "poder de las llaves» afirma que los obispos y sacerdotes, y sobre todo el obispo de Roma, pueden conceder indulgencias sobre las penas en el otro mundo para determinados períodos de tiempo, años, meses y días, $\mathrm{y}$, a veces, para siempre, como, por ejemplo, a los que van a Roma en cada fin de siglo.

Tal poder no se puede probar por la Santa Escritura ni por una deducción necesaria derivada de ella. Por otro lado, existen las mismas razones, según Marsilio, para negar esta afirmación que las aducidas sobre la imposición de la penitencia. Puede admitirse, continúa, que en virtud de sus oraciones por los pecadores, Dios disminuya en el otro mundo los castigos a los pecadores en cantidad y calidad, pero que sea en la proporción o de la manera indicada por los sacerdotes, nadie está obligado a creer en ello ${ }^{23}$.

Por las mismas razones, no corresponde a los sacerdotes, ni al obispo de Roma, indicar a todo fiel un ayuno de una duración determinada, prohibir alimentos, prescribir la interrupción de los trabajos civiles o manuales, declarar algunos días festivos... Todo esto recae en la autoridad del legislador humano o del Concilio General de todos los fieles cristianos ${ }^{24}$, o de los que, en lugar de todos los fieles, los represente en el Concilio General.

Los infieles, ¿deben ser obligados a confesar la fe cristiana? Responde Marsilio que no puede probarse por la Sagrada Escritura que así sea. De ello deduce que si las cruzadas se han realizado o se realizan para obligar a los infieles a confesar la fe de Cristo, no parecen algo meritorio en absoluto ${ }^{25}$. Si la finalidad de las mismas fuera obligar a los infieles a obedecer al príncipe o al pueblo romano en asuntos de preceptos civiles y para reclamar tributos convenientes, puesto que están obligados a ello jurídicamente,

\footnotetext{
${ }^{23}$ Marsilio de Padua. D.M., VII, 1.

${ }^{24}$ Marsilio de Padua. D.M., VII, 2.

${ }^{25}$ Marsilio de Padua. D.M., VII, 3.
} 
debería ser considerado meritorio por estar encaminado a la paz y a la tranquilidad de todos los hombres que viven en sociedad.

¿Qué es más grato a los ojos de Dios, peregrinar a los santuarios de los santos para manifestarles devoción, o distribuir entre los pobres, por devoción a dichos santos, los bienes o el dinero gastado en esas peregrinaciones? No se encuentra en la Escritura, señala Marsilio, ningún precepto o consejo relativo a las peregrinaciones, mientras que sí hay consejos formulados claramente, tanto en la ley antigua como en la nueva, respecto de las limosnas entre los pobres. Quien esto hiciera merecería cien veces más gracia a los ojos de Dios ${ }^{26}$.

\section{4.}

Hay una cuarta conclusión derivada del «poder de las llaves»: el obispo de Roma, y los otros obispos o sacerdotes a los que ha querido conceder este poder, pueden absolver o perdonar a cualquier fiel de Cristo el voto que haya realizado, de manera que no esté obligado, de ninguna manera, al cumplimiento de ese voto 27.

No pueden ser objeto de voto ni los preceptos de la ley divina ni de la ley humana: éstos deben, sin más, cumplirse. Deben versar sobre acciones permitidas, tanto por la ley humana como divina, y tienen por objeto adquirir un mérito o evitar un mal en este mundo o en el otro. El voto, al no versar sobre preceptos, depende de manera esencial del propio poder de decisión del hombre. El que hace un voto se da a sí mismo, sin coacción, un mandamiento que debe seguir.

Nadie está obligado ni sujeto a hacer un voto bajo pena de castigo en este mundo. Como hemos dicho, forma parte de las cosas permitidas o consejos. Sin embargo, una vez realizado, todo hombre está obligado a su cumplimiento bajo pena de castigo. $Y$

\footnotetext{
${ }^{26}$ Marsilio de Padua. D.M. VII, 4.

${ }^{27}$ Marsilio de Padua. D.M., VIII, 2. El voto «est promissio quaedam spontanea mente vel voce facta, de fiendo aliquo vel omittendo, sibi sufficienter cognito sive noto, propter finem aliquem obtinendum in praesenti saeculo vel venturo".
} 
si el que se ha comprometido civilmente no puede ser desligado de su compromiso sino por aquél con quien se ha comprometido de manera lícita, o por un juez superior a aquél que se ha comprometido y a la persona con la que se ha comprometido, nadie puede liberar de su voto al hombre que lo ha hecho, pues ni el obispo de Roma ni ningún otro obispo o sacerdote pueden ser juez ni superior del que ha realizado el voto, ni de Dios, ni de los espíritus bienaventurados a los que se le ha prometido consagrar el voto ${ }^{28}$.

¿Está permitido a quien ha hecho voto liberarse de él de manera que no esté obligado a su observancia posterior sin sufrir castigo en el otro mundo? Sí, desde la rectitud de conciencia y si se hace con la finalidad de actuar mejor o evitar lo peor y agradar más a Dios. En este caso, no cumple menos su voto o promesa a Dios. Puede, incluso, considerarse que lo cumple mejor. Este asunto debe, en cualquier caso, ser regulado según el juicio y la conciencia del que ha pronunciado el voto y según una interpretación favorable de la causa del que anula el voto, lo quiera o no un obispo o sacerdote ${ }^{29}$.

Sin embargo, quien anule un voto sin razón apremiante, será penado con un castigo temporal, por ser señal de inconstancia o de desdén y un mal ejemplo dado a los demás si se actúa de esta manera. Como subraya J. Quillet, «de ahí a concluir que es el poder secular quien debe ejercer legítimamente su poder coercitivo en ese campo, no hay más que un paso, que Marsilio da sin dudar; y puesto que una tal autoridad debe ejercerse, resulta que pertenecerá igualmente a sus competencias el hecho de eximir a alguien de un voto. En el plano humano, una promesa hecha

\footnotetext{
${ }^{28} \mathrm{~J}$. Quillet anota a esta propósito, op. cit., pág. 20: «El diálogo comprometido entre Dios y el que jura no deja apenas lugar a la intercesión del sacerdote, quien queriendo sancionar o liberar al que jura, comete el mismo abuso de poder que cuando excomulga o vende las indulgencias».

${ }^{29}$ Marsilio de Padua. D.M., IX, 2.
} 
puede ser retomada con el acuerdo del legislador humano o del príncipe del que es la emanación ${ }^{30}$.

¿Por qué se encuentra un desarrollo relativamente tan amplio sobre el voto en el Defensor Minor? Porque una de las consecuencias directas de esta doctrina será de orden inmediatamente político. En efecto, estas consideraciones están ligadas al problema del matrimonio Maultasch ${ }^{31}$, planteado en estos términos: ¿a quién compete la autoridad de disolverlo?

«El matrimonio es en cierta manera análogo al voto... Sólo en tanto que es signo de un sacramento en el contexto de la religión cristiana es algo espiritual. Pero es, sobre todo, un contrato humano... El príncipe no tiene poder espiritual propiamente dicho, pero dotado del poder político, debe conocer tanto los asuntos espirituales como los temporales, en la medida en que debe decidir entre lo lícito y lo ilícito en este mundo... Sólo el legislador humano o el príncipe tiene competencia para definir un matrimonio lícito, conceder una dispensa en caso de consanguinidad o proceder a la disolución de un matrimonio" ${ }^{32}$.

\section{5 .}

Del poder de las llaves se derivaba, por último, según los defensores de la teocracia pontificia, una atribución que ostentan los obispos y sacerdotes, y principalmente el obispo de Roma: excomulgar al pecador no arrepentido ${ }^{33}$.

La excomunión conlleva la privación o exclusión de una doble comunión o comunicación, según el Maestro de las Sentencias. Por un lado, el pecador excomulgado se ve privado de los sufragios y oraciones del resto de la Iglesia. Por otro, se ve excluido de la comunicación civil, de modo que ninguno de los demás fieles debe

\footnotetext{
${ }^{30}$ Quillet, J., op. cit., p. 21.

${ }^{31}$ Margarita Maultasch se divorció de Felipe VI de Valois y contrajo nuevo matrimonio en 1342 con Ludovico de Brandeburgo, hijo de Luís de Baviera.

${ }^{32}$ Quillet, J. op. cit., p. 21-22.

${ }^{33}$ Marsilio de Padua fue excomulgado, junto a Juan de Jandún, en 1327 por la bula Licet iuxta doctrinam de Juan XXII.
} 
participar con los pecadores en ningún acto privado, doméstico o civil, de palabra, de consentimiento o de hecho bajo pena de condenación eterna.

Marsilio niega que pueda demostrarse por la Santa Escritura que un pecador pueda ser privado de las plegarias de la Iglesia, pues esta acción no estaría destinada a edificar las almas, sino a destruirlas; ni que los sacerdotes tengan poder o autoridad para prohibir las cosas divinas a las comunidades de fieles que no los obedezcan, sino que, por el contrario, Cristo, según los Hechos de los Apóstoles, ha querido que sean disculpados como ha confirmado con su ejemplo y su acción San Pedro ${ }^{34}$.

Más taxativo, si cabe, se manifiesta Marsilio respecto del poder de un obispo, de un sacerdote o del obispo de Roma sobre la privación de comunicación civil. Tal autoridad tendría carácter coercitivo, alcanzando a los bienes y a las personas en la vida civil. Una autoridad como ésta no es propia de ninguna manera de los sacerdotes. En el caso de que así fuera, los sacerdotes podrían someter temporal y civilmente a todo individuo y a toda comunidad. En efecto, privando al pecador de la comunicación civil en este mundo, se le priva de las cosas necesarias para la vida. Desde ese momento, los sacerdotes o su congregación podrían infligir a todo pecador el castigo del exilio y la privación de ganancias o subsidios con los que el fiel de Cristo debe alimentarse y alimentar a su familia... «Ningún poder o autoridad para excomulgar espiritual o civilmente a los fieles, es decir, privarles de los sufragios espirituales o de la comunicación civil, ni el de emitir el interdicto sobre las comunidades de fieles privándolas del oficio divino, recae sobre los sacerdotes ${ }^{35}$.

¿En qué sentido conviene separar a los herejes de la sociedad de los fieles y privarlos de ella? ¿Sobre quién recae ese poder? La ley divina aconseja evitar a un criminal, no vivir en su compañía y no tener con él relaciones sociales ni conversaciones, sobre todo

\footnotetext{
${ }^{3}$ Marsilio de Padua. D.M., X, 2.

${ }^{35}$ Marsilio de Padua. D.M., X, 3.
} 
en lo referente a la fe cristiana y al culto divino. No prescribe, en absoluto, evitarlo y no comunicar con él en el dominio de los bienes civiles y los intercambios, puesto que en caso contrario el castigo recaería tanto o más sobre los fieles que no son criminales y que carecen de los bienes que los pecadores pueden aportar a causa de su función o de sus cargos y servicios en la vida en sociedad. Evitarlos de este modo no es un castigo real o personal, sino una cierta vergüenza y oprobio y nadie, por consiguiente, es privado de por sí de sus ventajas civiles reales y personales por precepto de la ley divina. La ley divina no ha dado a nadie la autoridad ni el poder coercitivo para castigar en sus bienes o en su persona en este mundo a un criminal, ni a los que están en relación con él, de cualquier manera que se quiera, y, sobre todo en el dominio de la comunicación civil ${ }^{36}$.

Por tanto, la ley divina no prescribe la excomunión en tanto que significa la privación de la comunicación civil. En cuanto tal, es un castigo de la ley humana, es decir, una manera de exilio, acompañada por un castigo tanto real como personal. $Y$ la autoridad de separar a los herejes por coacción o castigo en sus bienes o en su persona no corresponde a los sacerdotes sino a los príncipes laicos o al legislador humano $y$, por consiguiente, todos los bienes temporales de los herejes no deben ir a parar a los sacerdotes, sino al legislador o a los príncipes antedichos ${ }^{37}$.

4.

Negada a los sacerdotes la capacidad de dictar la ley o todo tipo de jurisdicción, analizadas las conclusiones que los defensores de la teocracia pontificia derivaban del denominado «poder de las llaves», se enfrenta Marsilio al tema clave para esta corriente de pensamiento: el obispo de Roma, el papa, tiene la plenitudo potestatis por su carácter de vicario y sucesor de Cristo, lo que le

\footnotetext{
${ }^{36}$ Marsilio de Padua. D.M., XV, 7.

${ }^{37}$ Marsilio de Padua. D.M., X, 6.
} 
confiere la plenitud de poder que éste tuvo como rey de reyes y señor de señores. «Este poder único que sólo el Papa posee es, en sentido especial, un «derecho divino»; confiere una peculiar superioridad, un poder de revisión e inspección sobre todas las demás formas de autoridad, tanto eclesiásticas como seculares. En este sentido, todo poder, tanto temporal como espiritual, reside en la iglesia y de él está investido el Papa. En esencia, la teoría equivale a una pretensión de soberanía universal que hace del Papa cabeza de todo el sistema jurídico, no como ejecutivo universal, sino como tribunal de autoridad final y como fuente del poder jurídico ${ }^{38}$.

Cristo fue una sola persona en dos naturalezas, la humana y la divina, por lo que fue verdadero Dios y verdadero hombre. Según Marsilio, en tanto que fue hombre y sacerdote humano, sucedieron a Cristo todos los apóstoles, obispos y sacerdotes. Sin embargo, en tanto que Dios y en tanto que Dios y hombre juntos, formas ambas en las que le había sido dado todo poder en el cielo y en la tierra, nadie puede suceder ni ha sucedido a Cristo, quien tuvo la plenitudo potestatis en virtud de su divinidad. Esta plenitud de poder no puede ni ha podido corresponder a ningún apóstol o sucesor, puesto que ninguno de entre ellos ha tenido ni tiune las dos naturalezas, divina y humana, en una sola persona ${ }^{39}$.

Argumentan algunos que la Iglesia Cristiana ha creído y dicho que San Pedro tuvo un poder en asuntos espirituales, y quizás en asuntos civiles o temporales, sobre todos los demás apóstoles, y que fue cabeza de la Iglesia. Dado que la Iglesia Universal no puede errar, concluyen que San Pedro tuvo la primacía antedicha sobre los apóstoles, y la Iglesia Romana sobre todas las demás, e infieren, además, que los obispos de Roma poseen esa primacía sobre todos los demás sacerdotes y obispos.

${ }^{38}$ Sabine, George: Historia de la Teoria Politica, Madrid, Fondo de Cultura Económica, 1990, p. 206.

${ }^{39}$ Marsilio de Padua, D.M., XI, 2. 
El Concilio General tiene por objeto definir «conjuntamente aquellas cosas tocantes a la ley divina que se hubieran presentado como dudosas y como con utilidad, conveniencia y necesidad de ser determinadas, y con ello también lo que sobre lo demás del ritual eclesiástico o culto divino, o lo que para el futuro, para la paz y tranquilidad de los fieles, se ha de ordenar» ${ }^{40}$. Sólo a él compete la versión autorizada de la ley divina contenida en la Escritura. Convocado de manera idónea ${ }^{41}$, el Concilio General no puede equivocarse, frente a las tesis defendidas por Ockham en la tercera parte del Dialogus, el «De Potestate Papae et Cleri»"2. Pronunciado el Concilio General, sus determinaciones deben ser creídas firmemente por necesidad de salvación eterna.

${ }^{40}$ Marsilio de Padua. El Defensor de la Paz, edición española a cargo de Luís Martínez Gómez, Madrid, Edit. Tecnos, 1989, II, XX, 2. En lo sucesivo citaremos todos los textos del D.P. por esta edición. El primer número romano corresponde a la primera, segunda o tercera dictio; el segundo número romano al capítulo correspondiente; el número arábigo se refiere al parágrafo.

${ }^{41}$ Marsilio de Padua, D.P. II, XXI, 1: «Pertenece sólo a la autoridad del legislador humano fiel, que no tiene superior por encima de sí, o a los que por el dicho legislador esa potestad les hubiera sido concedida, convocar el Concilio General». Por otro lado, señala Marsilio que el Concilio General para ser considerado como tal, requiere que la Iglesia Griega, que no debe ser considerada cismática, sea convocada de la manera requerida (D.M. XII, 4).

42 «Cristo, según Marsilio de Padua, habría promulgado en vano la ley de salvación eterna, si no hubiera instituido una autoridad capaz de revelar su sentido, cuando su interpretación presentara dificultades. Tal autoridad es la del Concilio General. Es esta tesis la que Ockham critica directamente porque la fe puede ser conservada por un pequeño número de fieles, e incluso por uno solo, sin que sea necesario que sea todo el conjunto. Para Marsilio, en efecto, fiel a la concepción aristotélica que ya había utilizado numerosas veces en el Defensor Pacis y según la cual muchos juntos juzgan mejor que uno o varios, sólo el concilio general, representando el conjunto de las comunidades religiosas o su parte preponderante tenía poder para decidir en los casos difíciles porque estaba inspirado por el propio Espíritu Santo.

Para Ockham esta tesis no solo es contestable sino que también dice que en las Escrituras no aparece que Dios hubiera prometido revelar la totalidad de sentido de sus palabras. De hecho Ockham es mucho más radical que Marsilio sobre este punto, porque su doctrina conduce, en definitiva, a la destrucción de la infabilidad de la Iglesia. Marsilio, a pesar de su extremismo aparente, es mucho más tradicional, en definitiva, como lo atestigua su réplica en el Defensor Minor». Quillet, J., op. cit., pp. 160-161. 
Sin embargo, si la Iglesia Universal se pronunciara sobre estas materias en base a un reconocimiento o costumbre, sin la deliberación de un Concilio General, esta creencia puede ser admitida por todos los fieles en razón de la costumbre, pero no como un dogma para la salvación eterna. De aquí que, siguiendo el reconocimiento y la costumbre, la Iglesia universal puede decir que San Pedro y la Iglesia Romana han tenido esa primacía sobre el resto de los obispos y de los sacerdotes y sobre todas las Iglesias en general, pero «no recuerdo haber leído ni en la Escritura, ni en nada que derivara necesariamente de la Escritura, que Dios o Cristo haya hecho él mismo esta concesión inmediata de preeminencia a San Pedro o a la Iglesia romana. Luego no es necesario creerlo para la salvación, puesto que no son artículos de fe, ni preceptos de la Escritura» ${ }^{43}$.

Es una razón de conveniencia la que aduce Marsilio como explicación de la preeminencia de San Pedro sobre los demás apóstoles y de la Iglesia Romana sobre las demás: esta superioridad procedería de la elección por los otros apóstoles o de su consentimiento ante la consideración de San Pedro como el. más respetable de los apóstoles. Del mismo modo, por la conveniencia, la tradición y por la constitución del Concilio General de los fieles cristianos o por la voluntad del supremo legislador humano, se explicaría la primacía de la Iglesia de Roma. En definitiva, «tales preeminencias han sido, más bien, concedidas al obispo y a la Iglesia de Roma por el legislador humano, fiel supremo, como lo demuestran escritos humanos auténticos» ${ }^{4}$.

¿Quién es el supremo legislador humano al que corresponde, como hemos visto, «convocar al Concilio General, determinar las personas idóneas (para ello), y hacer que el mismo sea congregado, celebrado y concluido según la forma debida, y castigar lícitamente, con potestad coactiva según la ley divina y humana, a los rebeldes que se resistan a venir y hacer allí lo necesario y útil,

${ }^{43}$ Marsilio de Padua. D.M., XI, 3.

4 Marsilio de Padua. D.M., XI, 3. 
igual que a los trasgresores, sacerdotes y no sacerdotes, clérigos y no clérigos»?45 "Supremus legislator humanus praesertim a tempore Christi usque in praesens tempus, et ante fortassis per aliqua tempora, fuit et est et esse debet universitatis hominum, qui coactivis legis praeceptis subesse debent, aut ipsorum valentior pars, in singulis regionibus atque provinciis" ${ }^{46}$. Y como este poder o autoridad ha sido transmitido por el conjunto de las provincias, o de su parte preponderante, al pueblo romano por su inmenso valor, el pueblo romano tuvo y tiene el poder de legislar sobre todas las demás provincias del mundo; $y$, si este pueblo ha transmitido a su príncipe el poder de legislar, de la misma manera hay que decir que su príncipe tiene este poder, que debe durar y durará razonablemente mientras no le sea retirado por el conjunto de las provincias al pueblo romano o por el pueblo romano a su príncipe. $Y$ tales poderes son revocados o revocables de la manera requerida, cuando el conjunto de las provincias, por ellas mismas o a través de sus representantes, o incluso el pueblo romano, se hayan reunido de manera conveniente y hayan hecho, ellos o su parte preponderante, una deliberación conveniente a tal revocación. Así es, en efecto, como ha sido entregado al pueblo romano y al Príncipe el poder de hacer las leyes, como lo atestiguan los relatos históricos serios, según Marsilio.

5.

La plenitudo potestatis de la Iglesia supone la negación de la autosuficiencia y autonomía de la sociedad civil y la servidumbre del poder temporal al poder espiritual, singular causa este hecho de la discordia contraria a la paz de los regímenes civiles, fuente ésta de lo mejor para el hombre, como señala Marsilio en el capítulo primero de la primera parte del Defensor Pacis. Decíamos que el Defensor Minor mantiene la coherencia y el objetivo básico

\footnotetext{
${ }^{45}$ Marsilio de Padua. D.P., II, XXI, 1.

${ }^{46}$ Marsilio de Padua. D.M., XII, 1.
} 
del conjunto de la obra de Marsilio: destruir en sus fundamentos la doctrina papal de la plenitudo potestatis, devolver a la autoridad política las atribuciones que le son propias tanto en el ámbito temporal como espiritual. Con este objetivo, Marsilio, en el Defensor Minor, cuestiona especialmente el poder espiritual de la Iglesia, raíz y fundamento, en definitiva, del resto de los poderes.

Dos son los frentes en los que centra el Defensor Minor su crítica, como hemos visto: las conclusiones que los defensores de la plenitudo potestatis del papado deducen del «poder de las llaves" y el primado pontificio. Previamente, por otro lado, resuelve qué debe entenderse por jurisdicción, derecho y ley y en quién radica el poder de dictarla y hacerla cumplir, conclusiones que, a su vez, enmarcan el análisis citado relativo al primado pontificio y al «poder de las llaves».

La ley hunde sus raíces en la voluntad popular y su rectitud consiste en ser expresión de la misma. No existen delitos temporales o espirituales objeto de poderes diferentes en este mundo: sólo existen delitos civiles, ya sean cometidos por sacerdotes o laicos, respecto de los cuales el uso coercitivo de la fuerza siempre corresponde a la autoridad civil. Sólo a ésta compete dictar la ley o jurisdicción en sentido estricto, y usar el poder coactivo connatural a la misma.

Con relación al poder de atar y desatar, rechaza las conclusiones derivadas por los defensores de la teocracia pontificia y precisa, y limita, el alcance del mismo: la confesión al sacerdote no es un precepto de la Sagrada Escritura. Basta confesar a solo Dios los pecados, es decir, reconocerlos y arrepentirse con el propósito de no cometer más. Puede, sin embargo, ser objeto de prescripción, y de posterior revocación, por un Concilio General. Cumplir penitencia en este mundo es un consejo, no un precepto. No se puede demostrar por la Santa Escritura que los obispos o sacerdotes puedan conceder indulgencias sobre las penas en el otro mundo para determinados períodos de tiempo. El juicio y la conciencia del que ha pronunciado el voto es la norma reguladora. Ningún poder o autoridad para excomulgar espiritual o civilmente 
a los fieles, es decir, privarles de los sufragios espirituales o de la comunicación civil, ni el de emitir el interdicto sobre las comunidades de fieles privándoles del oficio divino, recae sobre los sacerdotes. La excomunión, en tanto que significa la privación de la comunicación civil, es un castigo de la ley humana y, como tal, corresponde al legislador humano.

Por último, respecto del primado del Papa, afirma que no tiene ningún poder superior a los obispos o sacerdotes, como no lo tuvo nunca Pedro sobre los demás apóstoles. La estructura jerárquica de la Iglesia tiene un origen humano y como tal está subordinada a la autoridad civil. El órgano supremo de la Iglesia no es el romano pontífice sino el Concilio General, único interprete de la ley divina, y cuya convocatoria corresponde al Emperador, así como el garantizar coactivamente el cumplimiento de sus determinaciones. No existen, por consiguiente, dos poderes: la plenitudo potestatis corresponde en definitiva, y exclusivamente, al poder temporal, al poder civil.

La disparidad de juicios críticos sobre Marsilio de Padua es muy grande. Desde quienes lo consideran un profeta que se adelantó a los signos de su tiempo, un precursor, e incluso iniciador, de la Reforma, de la teoría de la separación de los poderes, paladín de la libertad de conciencia, el primero en conferir a la civitas las características del Estado moderno, a quienes señalan que su obra no constituye una ruptura radical con el pensamiento anterior e incluso consideran que se mueve en un marco medieval. En cualquier caso, como señala García Cue ${ }^{47}$, «la indiferencia ante su obra resulta imposible. Marsilio de Padua marca un hito importante en la transición del espíritu del medievo hacia la modernidad. Por todo ello puede afirmarse, sin exagerar, que su doctrina constituye uno de los capítulos más originales de la filosofía jurídico-política medieval».

${ }^{47}$ García Cue, J.R., op. cit., p. 148. 